\title{
Comparing Risk Components of Taxation Systems of Italy and the Russian Federation
}

\author{
Marina Malkina \\ Doctor of Sciences in Economics, Professor at Department of Economic Theory and Methodology \\ Head of Center of Microeconomics and Macroeconomics in Institute of Economics and Entrepreneurship in \\ Lobachevsky State University of Nizhni Novgorod, Russian Federation
}

Rodion Balakin

\begin{abstract}
Graduate student and PhD seekers at Department of Economic Theory and Methodology in Institute of Economics and Entrepreneurship in Lobachevsky State University of Nizhni Novgorod, Russian Federation, Lobachevsky State University of Nizhni Novgorod; E-mail:mmuri@yandex.ru, rodion-balakin@yandex.ru
\end{abstract}

Doi:10.5901/mjss.2016.v7n1p45

\section{Abstract}

The purpose of this article is assessment and comparison of the risk component in Italian and Russian tax systems, taking into account the influence of tax revenue structure, certain tax revenue irregularities and interrelation between tax revenues as such. For that reason, we described tax yield rate in both the countries at large and in terms of their basic taxes. On the basis of standard deviation indicator we assessed each tax risk within the framework of the taxation system of each country. Using $\mathrm{H}$. Markowitz's portfolio-based approach we analyzed the risk level of the tax system at large, relating to both the Russian Federation and Italy. In conclusion we inferred the reasons for the assessment given. The research was done on the basis of the official data provided by the state fiscal bodies and statistical authorities of the Russian Federation and Italy.

Keywords: the tax revenues, the tax burden, the risk of the tax system, standard deviation, correlation coefficient, H. Markowitz portfolio approach

\section{Introduction}

Tax systems assessment is usually carried out on the basis of the indicator of taxation yield that is determined as the relation of tax revenue to the domestic product of the area. However, such an assessment does not always fully describe the current state of the tax system of a particular country. Furthermore, countries with a similar level and structure of taxation system as well as a high resource mobility tend to even out in their economic development in course of time. However, the tax yield in the countries having a different level of economic development can be similar. It is true of Italy and the Russian Federation, in particular, where the level of tax yield is approximately the same, though both the structure and dynamics of tax revenue are considerably different.

To compare the tax systems and their effectiveness it is obviously necessary to consider additional parameters of the tax system. In simplistic terms, the above mentioned assessment can be inferred upon analyzing the structure of tax revenue in terms of the basic fiscal revenue source, as well as upon the dynamics of each tax revenue, which depends on the general economic changes in the country. In addition to that, tax revenue volatility is of primary importance, as well as its responsiveness to the changes of the macroeconomic situation and elasticity in terms of the real economy parameters.

The changes provided can be combined in a single parameter, that is the risk component of the tax system. The taxation system risk is here understood as primarily a measure of indicators volatility, which is assessed with a standard deviation and variance for any value.

Provided the risk is considered directly within the taxation system, there is a high degree of certainty with reference to the rules of taxation on the one hand. Any change to the taxation legislation is always widely discussed and it never comes unexpected to the tax-payer, for this reason it is not a risk per se. At the same time, tax revenue largely depends on how dynamic the economic activity in the country is, as well as on the resources flow between the countries and regions due to tax competition.

It all has its impact on how dynamic the tax basis is, primarily it concerns the taxes for which the above basis is mobile or exposed to the influence of market factors. Additionally, depending on how the taxation system rules are made, 
taxes can be pro-cyclical or counter-cyclical ones, and function as built-in stabilizers. The change of the rate of economic growth, structural shifts, the impact of global trends as well as their common influence on the taxation basis are not always highly predictable. This uncertainty is finally communicated to the taxation system. Even if the economic changes are largely prone to prediction, it is not always possible to promptly or fully adjust to them due to both objective and subjective reasons.

Another risk factor of the taxation system is the tax-payer's retreating to the background. The probability of such behavior depends on the institutional environment of a particular economy, strictness of legislation dealing with moneylaundry, as well as inevitability and effectiveness of the adapted measures or sanctions. Since future functioning of the taxation system is connected not only with the risks, but with uncertainty, which is very difficult to assess, here taxation system risk is evaluated on the basis of retrospective data about how the taxation systems of Russia and Italy functioned.

With this approach the taxation system risk is an estimated measure of tax revenue volatility that already took place in the recent past under the influence of some given factors, which failed to be adjusted to, rather than a forecasted uncertainty. For the purposes of assessment an adequate mathematical instrument is required, which allows to consider the following risk components: structural, dynamic and cyclic ones. Further comparing the yield and tax systems risk allows to give comparative evaluation of the effectiveness of the taxation systems of the countries in interest, as well as to expose their current state and developmental trends.

\section{Literature Review}

A method to assess taxation systems risk is a dubious issue in the financial economics. Exploring the issues in the above field the main focus is made on either analyzing how unevenly the burden of taxation is divided (Baer W. \& Galvao A.F. Jr.: 2008; Fukuda K.: 2008; Gujarathi M. \& Feldmann D.: 2006), this way the risk of the taxation system per se is not taken into consideration, or on the risk assessment at large (Haim S. \& Shlomo Y.: 1984), this way the taxation system is not considered as a subject of research.

It is customary to use VaR (value at risk) when assessing risks. It is a monetary estimate which is not to be exceeded by losses expected at a specified probability within a certain period.

In particular some researchers used VaR to assess the effectiveness of the taxation policy carried out in certain states of the USA (Cornia G.C. \& Nelson R.D.: 2010), as well as to add to the calculation of economic growth elasticity depending on the volatility of the collected taxes (Felix R.A.: 2008; Fricke H. \& Süssmuth B.). Moreover, in some research $\mathrm{VaR}$ is used as a basis for defining the amount of insurance fund in case of crisis and cut in tax revenue (Salin V. \& Patron E. \& Stallmann J. I.: 2004). In our paper to assess the risk we use weighted standard deviation of the tax yield of a certain tax, specified years ratio within the gross regional product considered.

H. Markowitz's portfolio-based approach, which we use as a basis for taxation systems risk assessment, was originally used to determine the risk of investment portfolio (Deng G.F. \& Lin W.T. \& Lo C.C.: 2012; Haim S. \& Shlomo Y.: 1984; Soleimani H. \& Golmakani H.R. \& Salimi M.H.: 2009; Wilford D. S.: 2012). For the purposes of assessing the risk of investment portfolio we used this approach in the paper (Malkina M. Yu. \& Balakin R.V.: 2015; Malkina M. Yu. \& Balakin R.V.: 2014), where panel data of the Russian federation regions were used.

Meanwhile, we found a set of similar in their character, while not identical research papers which solve the task of optimizing the structure of the taxation portfolio within an economic cycle. The target function is a risk indicator (tax revenue variance) which aims at its minimizing.

Portfolio risk minimization was used in relation with this approach in order to explore both whether the taxation burden is enough, as well as whether the taxation portfolio is well-balanced. The latter characteristic influences economic growth through uncertainty and expectations (Seegert N.: 2012). In another expanded model there is used regression analysis in order to determine the figures of taxation basis elasticity depending on the yield (Garrett T.A.: 2006). The result obtained through a set of empirical studies enables us to build an effective border of relation between the yield and risk of the taxation systems. The review of the approaches is provided in the paper (Albrecht W.G.: 2013).

Before moving further to a detailed description of methods, it is necessary to make the following reservation. Markowitz's portfolio approach is being used to calculate the risk. Prospectively, it is possible to determine the optimal tax portfolio which considers the characteristics of all comprised taxes. Making such an optimal portfolio implies making up recommendations connected with changing the tax legislation. The difference between taxes and investment tools is that the former are statutory, therefore optimizing "tax portfolio" is not defined by the will of investors, but requires a legislative initiative.

Since the tax-payer's reaction to such changes can turn hard to predict and slow, optimizing the portfolio can lead to a sub-optimal result, which will require further correction. While changing the taxations legislation is connected with 
high transactional costs, as compared to the behavior of investors in the stock market considering this factor makes this quality of being sub-optimal appropriate.

Therefore, applying the portfolio approach with the purpose of assessing taxation systems is considered to be reasonable, especially in situations when the radical changes in the taxation legislation require reasoning.

Similar to the investment portfolio, the tax portfolio risk can be assessed on the basis of three factors. The first factor is a temporary volatility of tax yield of different taxes which primarily depends on the dynamics of the business activity in the country. The second factor is an interconnection of different taxes revenue which is assessed with a covariation indicator, which in its turn increases the risk. The third factor is a share of different taxes (more or less depending on the market factors) in the overall tax revenue. Hereafter there is applied a standard mathematical tool comprising all the three factors, which was developed by Markowitz.

We used a deflation method, which had earlier been employed, in order to intertemporarily compare and adequately aggregate tax revenue that belong to different times. Additionally, we used the Pearson's correlation weighted ratio (Bunescu L. \& Comaniciu C.: 2014), which allows to consider different scales of objects of research.

\section{Research Methodology}

Since the suggested method of assessing the taxation systems risks means dealing with time series of indicators, in order to correctly compare and aggregate them, we priced all the input data within a year to cover the whole research term. Both for the Russian Federation and Italy we priced the data as of 2010. For the purposes of deflation we used a deflation index of the GDP:

$$
T R_{i k}^{*}=\frac{T R_{i k}}{I^{P}} \text {, where }
$$

$T R_{i k}$ is a $k$-tax revenue in a $i$-year priced as of the current year (i-year), $\mathbb{P}$ is a deflation index, calculated as a relation of the GDP in current prices to the GDP in basic year prices, $T R^{*}{ }_{i k}$ is a $k$ - tax revenue in a $i$-year in basic year prices.

To adequately compare the volume of tax amounts between the two countries we used a tax rate return calculated as the relation of the tax revenue to the GDP of the country:

$$
T B_{i k}=\frac{T R_{i k}}{G D P_{i}} \text {, where }
$$

$T B^{*}$ ik is $k$-tax return in a $i$-year (in the basic year prices), $G D P_{i}^{*}-G D P$ in the $i$-year in the basic year prices.

The first stage of tax system risk assessment at large is each tax risk assessment, which is part of the above mentioned system. For this purpose we used a weighted standard deviation indicator to assess the revenue of each tax on a country scale.

$$
\sigma_{k}=\sqrt{\sum_{i=1}^{n}\left(T B_{i k}^{*}-\overline{T B_{k}^{*}}\right)^{2} \times s_{i}} \text {, where }
$$

$\sigma_{k}$ is a standard deviation of $k$-tax revenue, $s_{i}-$ GDP share in a $i$-year in a total GDP sum in the basic year prices

$$
\text { for the whole term of research, which is calculated by the following formula: } s_{i=1}=\frac{G D P_{i}^{*}}{\sum_{i=1}^{n} G D P_{i}^{*}}, \overline{T B_{k}^{*}} \text { is an average amount of }
$$
$k$ - tax revenue for the whole term of research considering each year share in the GDP, which is calculated by the following formula: $\overline{T B_{k}^{*}}=\sum_{i=1}^{n}\left(T B_{i k}^{*} \times s_{i}\right)$.

In order to assess the effectiveness of each particular tax we used tax system effectiveness index which is a relation of risk-free return to the tax risk:

$$
S_{k}=\frac{\overline{T B_{k}^{*}}}{\sigma_{k}}
$$

The second stage of tax system risk assessment is applying $\mathrm{H}$. Markowitz - W. Sharpe's portfolio approach. In this case the tax system risk can be calculated as follows:

$$
\theta=\sqrt{\sum_{k=1}^{m} \sum_{l=1}^{m} \operatorname{cov}_{k, l} \times q_{k} \times q_{l}} \times 100 \% \text {, where }
$$


$\theta$ is a "portfolio" tax risk, $k, l$ are taxes included in the "portfolio" $(k, l=1, \vec{m}), q_{k(l)}$ is a $k$-tax share $(l-\operatorname{tax})$ in total tax

revenues over the whole term of research, which is calculated by the formula: $q_{k(l)}=\frac{\sum_{i=1}^{n} T R_{i k(l)}^{*}}{\sum_{k=1}^{m} \sum_{i=1}^{n} T R_{i k(l)}^{*}}$.

We similarly calculated tax system effectiveness index for the tax system at large by the following formula:

$S=\frac{T B}{\theta}$, where

$T B$ is a general level of return of all taxes over the whole term of research, where $\sum_{i=1}^{n} G D P_{i}^{*}$.

The next stage is assessing the degree of relation between risk and tax return within each tax system under analysis on the basis of Pearson's correlation weighted ratio, where each tax total shares are used as scales:

$$
R=\frac{\sum_{k=1}^{m}\left(\overline{T B_{k}^{*}}-\overline{T B}\right) \times\left(\sigma_{k}-\bar{\sigma}\right) \times q_{k}}{\sqrt{\sum_{k=1}^{m}\left(\left(\overline{T B_{k}^{*}}-\overline{T B}\right)^{2} \times q_{k}\right) \times \sum_{k=1}^{m}\left(\left(\sigma_{k}-\bar{\sigma}\right)^{2} \times q_{k}\right)}} \text {, where }
$$

$\overline{T B}$ and $\bar{\sigma}$ are weighted values for tax revenue and standard deviation calculated correspondingly by the following formulae: $\overline{T B}=\sum_{k=1}^{m}\left(\overline{T B_{k}^{*}} \times q_{k}\right) ; \bar{\sigma}=\sum_{k=1}^{m}\left(\sigma_{k} \times q_{k}\right)$

The starting base for the study is official data provided by the state bodies and authorities. In the Russian Federation the data was provided by the Federal Tax Service of the Russian Federation, which issues a reporting form №1-HM "Report on tax, levy and other statutory charges and payment to the budget of the Russian Federation". The currently available data is that of the years from 2006 till 2012; this data was used in the research paper.

GDP was used as the tax assessment base (the data provided by the Federal State Statistics Service).

The following Russian Federation taxes have come under analysis: income tax, value added tax, personal income tax, excise taxes, property taxes (personal property tax and company property tax, gaming tax, transportation taxes, land tax); natural resource tax (the larger part is contributed through mineral extraction tax); state duty and special tax regimes (unified agricultural tax, simplified taxation system and unified tax on imputed income).

The basis for research in terms of characterizing the Italian tax system is the data about tax revenues in the years 2002-2003. The major source of the above data is the reports of the Department of Finance (II Dipartimento delle Finanze) of the Ministry of Economics and Finance (Ministero dell'Economia e delle Finanze). The Department makes monthly reports (Appendici statistiche e Guida normativa al Bollettino) about tax revenues. The source of additional data is the database of the National Institute for Statistics (Istituto nazionale di statistica - Istat). The data provided by the Institute allows systematizing the departmental data and presenting the information objectively.

To conclude, according to the reports the Italian tax system includes 14 most revenue giving taxes, which can be grouped in the following categories: direct taxes (personal income taxes, company income taxes, capital levy, other direct taxes), business taxes, administrative levy (registration fees, stamps, insurance tax, mortgage tax, state concessions), tax on commodity and services flow (value added tax, excise duties on energy utilities and their products, vehicle taxes), consumption, monopoly and lottery taxes (TV and radio license duty, excise duty on consumption, lottery revenue). The latter three groups belong to group of indirect taxes. There is also a group of "other indirect taxes" comprising the taxes that do not fall under the above mentioned classification.

\section{Findings and Discussion}

Before making any research conclusions, it is essential to characterize the situation in the Russian Federation and Italy in terms of the condition of their tax systems. There are tax revenues calculated upon the data of the Russian federation and Italy in Tables 1 and 2 respectively. 
Table 1. Major taxes revenue (group of taxes revenue) in Italy in the years 2002-2013 (\% to GDP)

\begin{tabular}{|c|c|c|c|c|c|c|c|c|c|c|c|c|c|}
\hline & & 2002 & 2003 & 2004 & 2005 & 2006 & 2007 & 2008 & 2009 & 2010 & 2011 & 2012 & 2013 \\
\hline \multirow{5}{*}{$\mathscr{\mathscr { d }}$} & Personal income tax & 9.32 & 9.21 & 9.06 & 9.21 & 9.44 & 9.55 & 10.03 & 10.16 & 10.35 & 10.12 & 10.23 & 10,25 \\
\hline & Company income tax & 2.23 & 2.12 & 2.03 & 2.29 & 2.58 & 3.17 & 2.95 & 2.46 & 2.40 & 2.30 & 2.37 & 2,57 \\
\hline & Capital levy & 0.74 & 0.60 & 0.54 & 0.54 & 0.65 & 0.75 & 0.83 & 0.84 & 0.45 & 0.42 & 0.64 & 0,73 \\
\hline & Other direct taxes & 0.75 & 0.60 & 0.81 & 0.35 & 0.76 & 0.42 & 0.42 & 1.01 & 0.56 & 0.72 & 0.98 & 1,03 \\
\hline & TOTAL in group & 13.03 & 12.53 & 12.43 & 12.38 & 13.42 & 13.89 & 14.23 & 14.48 & 13.76 & 13.57 & 14.23 & 14,58 \\
\hline \multirow{6}{*}{ 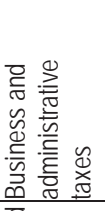 } & Registration fees & 0.28 & 0.29 & 0.31 & 0.31 & 0.33 & 0.35 & 0.33 & 0.30 & 0.31 & 0.28 & 0.25 & 0,23 \\
\hline & Stamps & 0.28 & 0.27 & 0.36 & 0.34 & 0.36 & 0.35 & 0.34 & 0.36 & 0.34 & 0.33 & 0.37 & 0,47 \\
\hline & Insurance tax & 0.19 & 0.19 & 0.22 & 0.19 & 0.18 & 0.18 & 0.19 & 0.23 & 0.21 & 0.18 & 0.18 & 0,18 \\
\hline & Mortgage tax & 0.08 & 0.08 & 0.09 & 0.09 & 0.13 & 0.15 & 0.14 & 0.13 & 0.13 & 0.12 & 0.11 & 0,11 \\
\hline & State concessions & 0.07 & 0.09 & 0.08 & 0.09 & 0.09 & 0.10 & 0.10 & 0.10 & 0.10 & 0.10 & 0.10 & 0,10 \\
\hline & TOTAL in group & 0.90 & 0.92 & 1.06 & 1.01 & 1.09 & 1.13 & 1.10 & 1.13 & 1.09 & 1.02 & 1.02 & 1,08 \\
\hline \multirow{4}{*}{ 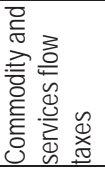 } & Value added tax & 7.00 & 7.32 & 7.01 & 7.15 & 7.48 & 7.53 & 7.32 & 7.10 & 7.19 & 7.23 & 7.22 & 7,14 \\
\hline & $\begin{array}{l}\text { Excise duties on energy utilities and } \\
\text { their products }\end{array}$ & 1.54 & 1.51 & 1.39 & 1.42 & 1.38 & 1.26 & 1.24 & 1.32 & 1.25 & 1.24 & 1.51 & 1,50 \\
\hline & Vehicle taxes & 0.01 & 0.05 & 0.06 & 0.04 & 0.04 & 0.04 & 0.04 & 0.04 & 0.04 & 0.04 & 0.04 & 0,04 \\
\hline & TOTAL in group & 8.55 & 8.88 & 8.46 & 8.61 & 8.90 & 8.83 & 8.60 & 8.46 & 8.48 & 8.51 & 8.76 & 8,68 \\
\hline \multirow{6}{*}{ 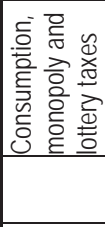 } & TV and radio license duty & 0.10 & 0.10 & 0.10 & 0.10 & 0.10 & 0.10 & 0.10 & 0.11 & 0.11 & 0.11 & 0.11 & 0,11 \\
\hline & Excise duty on consumption & 1.01 & 1.06 & 1.05 & 1.08 & 1.10 & 1.07 & 0.97 & 1.13 & 1.12 & 1.13 & 1.17 & 1,12 \\
\hline & Lottery taxes & 0.54 & 0.40 & 0.98 & 0.79 & 0.61 & 0.69 & 0.65 & 0.76 & 0.69 & 0.74 & 0.68 & 0,68 \\
\hline & TOTAL in group & 1.66 & 1.57 & 2.13 & 1.96 & 1.81 & 1.86 & 1.72 & 2.00 & 1.92 & 1.97 & 1.96 & 1,90 \\
\hline & Other indirect taxes & 0.55 & 0.72 & 0.89 & 0.47 & 0.52 & 0.23 & 0.23 & 0.24 & 0.22 & 0.29 & 0.20 & 0,21 \\
\hline & TOTAL in groups & 11.65 & 12.10 & 12.54 & 12.06 & 12.31 & 12.05 & 11.65 & 11.83 & 11.71 & 11.79 & 11.94 & 11,88 \\
\hline \multicolumn{2}{|c|}{ TOTAL RETURN } & 24,68 & 24.68 & 24.63 & 24.9 & 24.45 & 25.73 & 25.9 & 25.88 & 26.31 & 25.47 & 25.36 & 26.17 \\
\hline
\end{tabular}

Table 2. Major taxes revenue (group of taxes revenue) in the Russian Federation in the years 2006 - 2012 (\% to GDP)

\begin{tabular}{|lccccccc|}
\hline & $\mathbf{2 0 0 6}$ & $\mathbf{2 0 0 7}$ & $\mathbf{2 0 0 8}$ & $\mathbf{2 0 0 9}$ & $\mathbf{2 0 1 0}$ & $\mathbf{2 0 1 1}$ & $\mathbf{2 0 1 2}$ \\
\hline Profit tax & 7.45 & 7.72 & 7.42 & 3.97 & 4.73 & 5.03 & 4.75 \\
Personal income tax & 4.12 & 4.49 & 4.86 & 5.13 & 4.68 & 4.34 & 4.48 \\
Value added tax & 4.14 & 4.96 & 2.97 & 3.72 & 3.56 & 3.92 & 3.84 \\
Excise duties & 1.12 & 1.04 & 0.92 & 1.01 & 1.17 & 1.34 & 1.57 \\
Property tax & 1.38 & 1.47 & 1.45 & 1.78 & 1.68 & 1.50 & 1.58 \\
Natural resources taxes & 5.46 & 4.87 & 5.87 & 3.99 & 4.65 & 5.35 & 5.61 \\
State duties & 0.03 & 0.03 & 0.03 & 0.05 & 0.05 & 0.04 & 0.04 \\
Special tax regimes & 0.49 & 0.50 & 0.54 & 0.53 & 0.54 & 0.51 & 0.53 \\
\hline TOTAL RETURN & 24.19 & 25.08 & 24.07 & 20.17 & 21.05 & 22.03 & 22.41 \\
\hline
\end{tabular}

Comparing the tax systems of the Russian Federation and Italy brings us to a number of conclusions. The first of them is that the general level of tax revenues in the Russian Federation and Italy is generally comparable, though in Italy it is inconsiderably higher than that in the Russian federation.

Secondly, in Italy there is a tendency towards a rise in the tax revenues: from 2002 till 2013 it gained $1.5 \%$ of the GDP. Whereas in the Russian Federation, on the contrary, there was a tendency towards tax revenue decrease: from 2006 till 2012 the level dropped by $1.8 \%$.

Thirdly, the tax burden in the Russian Federation is evenly distributed among all the taxes. In the Russian Federation there are only two taxes which have a revenue less than $1 \%$ of the GDP, while in Italy there are five taxes that are over the level. For two types of excise duties the increase is not considerable - not more than $1.5 \%$, while two thirds of all tax revenue usually come from the two leading taxes - personal income tax and value added tax.

Company tax revenues in Italy are about $3 \%$ of the GDP, which is considerably less than the revenue of the profit tax in the Russian Federation (6.37\%), which before the crisis was $7.5 \%$. What is more, to compare the assessments it is important to consider that in the Russian Federation besides a profit tax there is natural resources tax and special tax regimes, which are based upon the income of the corresponding companies and fields.

The above mentioned three company income taxes In Russia account for approximately $10 \%$ of the GDP account which corresponds to $50.72 \%$ of all tax revenues to the budget. It is a considerably higher estimate than that of a similar 
revenue in the Italian tax system, where the company income taxes are $9.65 \%$ of all tax revenues.

At the same time in the Italian tax system the revenue coming from value added tax and personal income tax and is considerably bigger than that in the Russian Federation.

The revenue that comes from the value added tax in Italy was about $7-7.5 \%$ of the GDP, and within 11 years varied inconsiderably compared to the same term in Russia.

In the Russian Federation the revenue from the value added tax is on average by 1.89 times smaller compared to Italy. It is one of the most unstable taxes, its revenue in the years 2007-2008 was about $2.94-4.97 \%$ of the GDP.

The personal income tax revenue in the Russian Federation is considerably smaller than that in Italy $(4.5 \%$ against $10 \%$ of the GDP).

Upon considering the structure and variability of the tax revenues in Italy and the Russian Federation, it is reasonable to give qualitative assessment of the Russian and Italian tax systems risk. For the purpose of adequate comparison it is obligatory to consider the same term of research. For instance, if further tax system risk assessment in Italy is carried out upon the data from the year 2002, while in Russia the term of assessment is that from 2006, in the manner used to assess certain taxes, it will lead to the fact that Italian indicators will be based upon a double number of observations. It is noteworthy that for the Russian Federation almost half of the above observations accounts for the years of crisis, characterized by a general tendency towards the decrease in tax revenues and therefore a higher risk for the tax system at large. Whereas, Italian observation term covers non-crisis years as well, which undoubtedly has a beneficial impact on the end result. This is why we worked out two variants of risk assessment for Italy, though the comparison with the Russian federation is drawn upon the data from the year 2006.

In Tables 3 and 4 there are indicators which characterize the Italian and Russian tax systems risk assessment respectively. In the bottom lines there is data about the general cross-country tax revenue level and weighted standard deviation ratio inclusive of the shares of the taxes in tax return, as well as their correlation (tax system effectiveness index).

To give a comparative risk assessment in tax systems at large it is necessary for the systems to include the same number of elements. For this purpose we united the taxes in the Italian taxation system in accordance with their economic content so that in the end to get the same number of groups as there are in the Russian taxation system, that is eight.

As it follows from Table 3, it has not made a considerable impact on the tax system risk assessment.

Table 3. Indicators which characterize the revenue and risk of certain taxes within the Italian taxation systems

\begin{tabular}{|c|c|c|c|c|c|c|c|}
\hline & & \multicolumn{3}{|c|}{ According to the data from the year 2002} & \multicolumn{3}{|c|}{ According to the data from the year 2006} \\
\hline & & 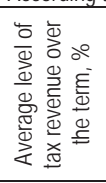 & 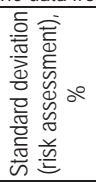 & 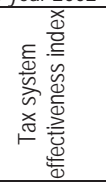 & 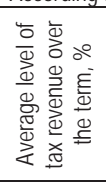 & 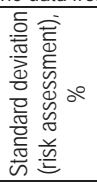 & 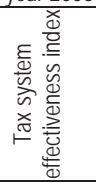 \\
\hline \multirow{5}{*}{ 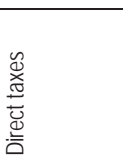 } & Personal income tax & 9.74 & 0.47 & 20.91 & 10.01 & 0.32 & 31,42 \\
\hline & Company income tax & 2.46 & 0.32 & 7.69 & 2.61 & 0.29 & 9,02 \\
\hline & Capital levy & 0.64 & 0.13 & 4.84 & 0.66 & 0.15 & 4,50 \\
\hline & Other direct taxes & 0.70 & 0.23 & 3.07 & 0.73 & 0.24 & 3,06 \\
\hline & TOTAL in the group & 13.54 & 0.22 & 62.01 & 14.01 & 0.16 & 86,11 \\
\hline \multirow{6}{*}{ 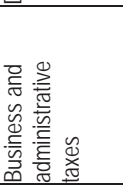 } & Registration fees & 0.30 & 0.03 & 9.10 & 0.30 & 0.04 & 7,75 \\
\hline & Stamps & 0.35 & 0.05 & 7.42 & 0.37 & 0.04 & 9,14 \\
\hline & Insurance tax & 0.19 & 0.02 & 11.93 & 0.19 & 0.02 & 11,40 \\
\hline & Mortgage tax & 0.12 & 0.02 & 4.89 & 0.13 & 0.01 & 9,47 \\
\hline & State concessions & 0.09 & 0.01 & 9.28 & 0.10 & 0.00 & 19,70 \\
\hline & TOTAL in the group & 1.05 & 0.001 & 813.04 & 1.08 & 0.001 & 886,47 \\
\hline \multirow{4}{*}{ 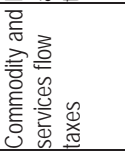 } & Value added tax & 7.23 & 0.16 & 45.40 & 7.28 & 0.15 & 49,84 \\
\hline & $\begin{array}{l}\text { Excise duties on energy utilities and } \\
\text { their products }\end{array}$ & 1.38 & 0.11 & 12.46 & 1.34 & 0.10 & 12,74 \\
\hline & Vehicle taxes & 0.04 & 0.01 & 3.37 & 0.04 & 0.00 & 46,37 \\
\hline & TOTAL in the group & 8.65 & 0.05 & 169.09 & 8.66 & 0.05 & 186,32 \\
\hline \multirow{6}{*}{ 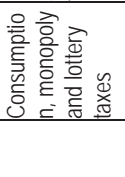 } & TV and radio license duty & 0.10 & 0.00 & 33.13 & 0.10 & 0.00 & 28,59 \\
\hline & Excise duty on consumption & 1.08 & 0.05 & 20.04 & 1.10 & 0.06 & 19,32 \\
\hline & Lottery taxes & 0.68 & 0.13 & 5.15 & 0.69 & 0.04 & 15,97 \\
\hline & TOTAL in the group & 1.87 & 0.01 & 318.52 & 1.89 & 0.004 & 528,94 \\
\hline & Other indirect taxes & 0.40 & 0.22 & 1.80 & 0.27 & 0.10 & 2,72 \\
\hline & TOTAL in the group & 11.96 & 0.06 & 193.80 & 11.90 & 0.05 & 227,62 \\
\hline
\end{tabular}




\begin{tabular}{|c|c|c|c|c|c|c|}
\hline Total return - 14 taxes & 25,50 & 0.28 & 91.05 & 25.91 & 0.22 & 120.52 \\
\hline Total return -8 consolidated taxes & 25,50 & 0.29 & 88.14 & 25.91 & 0.22 & 115.69 \\
\hline
\end{tabular}

Table 4. Indicators which characterize the revenue and risk of certain taxes within the Russian taxation systems in the years $2006-2012$

\begin{tabular}{|lccc|}
\hline & $\begin{array}{c}\text { Average level of tax revenue } \\
\text { over the term, } \%\end{array}$ & $\begin{array}{c}\text { Standard deviation (risk } \\
\text { assessment), } \%\end{array}$ & $\begin{array}{c}\text { Tax system effectiveness } \\
\text { index }\end{array}$ \\
\hline Profit tax & 6.37 & 1.05 & 6.04 \\
Personal income tax & 4.64 & 0.32 & 14.57 \\
Value added tax & 3.83 & 0.57 & 6.72 \\
Excise duties & 1.18 & 0.21 & 5.68 \\
Property taxes & 1.55 & 0.12 & 12.41 \\
Natural resources tax & 4.66 & 0.48 & 9.63 \\
State duty & 0.04 & 0.01 & 4.96 \\
Special tax regimes & 0.53 & 0.02 & 23.85 \\
\hline TOTAL RETURN & 22.78 & 0.57 & 39.72 \\
\hline
\end{tabular}

The first conclusion that is to be made upon the analysis of the tables provided above is a considerably high value of the risk component of the Russian taxes in comparison with the Italian ones. It is noticeable at the level of the total return: the value of the weighted standard deviation of tax return in Russia is almost 2.6 times higher than that one in Italy (provided the matching terms of research are used). Another very typical example makes the phenomenon even more observable. Personal income tax is the most risky tax within the framework of the Italian taxation system. While in the Russian Federation this tax ranks fourth among the eight according to the above given factor. The risk level is equal for both. It is 0.32. We agreed to consider the value based on the analysis of data starting from the year 2006. If calculation is made starting from the year 2002, the risk assessment within the Italian tax system framework increases and equals 0.47 .

The fact that risk increases if the term of research extends is noteworthy as a common tendency of approximately all taxes. The tendency is highly characteristic of more productive taxes; on average the risk assessment increases by 1.5 times if the term of research extends for 4 years.

A higher risk of the Russian tax system compared to that in Italy is provided due to a higher risk assessment of more productive taxes within the framework of the Russian tax system.

For instance, profit tax in the Russian Federation is the most risky one, compared to that one in Italy where it ranks second after the personal income tax.

The risk assessment of the profit tax in the Russian Federation is by 3.62 times higher than that for the Italian tax. The surpass for the value added tax is even more considerable: 3.8 times. It should be noted that within the Russian tax system framework this tax ranks second, while within the Italian one it ranks fourth. It is undoubtedly a high rank considering that the Italian portfolio comprises 14 taxes, while the leading ones in terms of the risk component value are direct taxes. Value added tax which is a leader among indirect taxes in terms of risk leaves behind just one tax (capital levy), which comes fifth.

In terms of Russian reality it is impossible to state an advantage of direct or indirect taxes as to how they relate to the risk component value. The value of the calculated risk for excise duties is by 3.5 times higher than that of the similar tax group in Italy where these taxes in terms of the risk component value rank eighth among fourteen taxes referred to above.

To conclude this part or research it should be noted that the risk assessment for Russian taxes is generally higher. It is a noteworthy fact that the taxes having the highest values of risk component undoubtedly are similar to one another within the tax systems of Italy and the Russian federation, though their sequence is different. With a comparatively high risk of the profit tax and value added tax in both taxation systems, in Italy personal income tax is an absolute leader, while in Russia this tax is in the middle of the list. Their risk levels match although.

The calculated values of standard deviations characterize the situation in relation to a particular tax, rather than a situation in general. Their general analysis, though, allows for an assumption that the Russian tax system is more risky than that of Italy. To check the hypothesis we calculated the following part of research. The results of risk assessment for a detailed and comparable tax portfolio are provided in Table 5. 
Table 5. Factors characterizing the risk component of Russian and Italian tax systems

\begin{tabular}{|lccc|}
\hline \multicolumn{3}{|c|}{ Portfolio risk, \% Tax system effectiveness index Weighted correlation ratio } \\
\hline $\begin{array}{l}\text { Russian taxation system: } \\
\text { Portfolio comprising 8 taxes (tax groups) starting from the year 2006 }\end{array}$ & 0.3456 & 65.93 & 0.85 \\
\hline $\begin{array}{llll}\text { Italian taxation system: } \\
\text { Portfolio comprising 8 taxes (tax groups) starting from the year 2006 }\end{array}$ & 0.0816 & 317.39 & 0.49 \\
Portfolio comprising 14 taxes (tax groups) starting from the year 2006 & 0.0769 & 337.08 & 0.67 \\
Portfolio comprising 8 taxes (tax groups) starting from the year 2002 & 0.1893 & 134.75 & 0.48 \\
Portfolio comprising 14 taxes (tax groups) starting from the year 2002 & 0.1970 & 129.47 & 0.72 \\
\hline
\end{tabular}

As it follows from the Table, Russian tax system risk assessment (0.3456) is by far than 4 times as high as the Italian tax system risk assessment (0.0816). This fact bears out the above claim about a high risk of the Russian taxation system. Though, when applying a portfolio approach, risk excess proved to be higher, than the one when a weighed value was used (see Tables 3 and 4), when it was estimated as excessing by 2.6 times.

The explanation of this fact can be found in the inverse co-variation of some Italian taxes return, which testifies to a better in-country risk hedging. The latter is important in terms of a worse diversification of the Italian tax systems which was revealed earlier.

The discrepancy in the values for tax system effectiveness index for Russia and Italy (65.93 and 317.08 respectively) is generally determined by the difference in the risk indicators, because the overall level of tax revenue is similarly the same in both the countries.

It is interesting to follow the risk assessment which was obtained for the Italian tax system in its relation to the term of research and the number of elements in the portfolio.

As seen from the results, the portfolio specification has little impact on the Italian tax system risk. The explanation can be found in the fact that extended groups include the taxes which show the same regular patterns of dynamics.

A different conclusion is made when the term of research is changed. Its impact on the risk assessment proves to be considerable.

If a set consisting of an equal number of elements is considered, for the eight of them risk excess for the period of 11 years over that of 8 years is 2.32 times, while for a set of 14 elements it is slightly bigger -2.56 times. The explanation can be found in the fact that for Italy expanding the term of research falls on the years (2002-2006) that are less beneficial in terms of economics than in Russia, which at that time used the advantage of rising oil prices.

At the same time adding earlier terms of research causes advance decrease of Tax system effectiveness index in the Italian tax system. The reason for this can be the fact that more considerable fluctuations around the rising trend of an average return are more characteristic for a longer term of research of the Italian tax system than for a shorter one.

The last of all considered indicators - the correlation ratio in all considered variants proves a direct link between return and some taxes risk as well as the risk of the taxation systems of the countries in question at large.

It is noteworthy that unlike risk assessment, the term of research does not considerably affect its value, while extending the portfolio from 8 to 14 taxes increases it by half. Another notable issue is that under otherwise equal conditions for the Russian tax system this ratio is considerably higher, though it contains fewer elements.

\section{Concluding Remarks}

Summing the paper up, it should be noted that in spite of the similarity between the Russian and Italian levels of tax return, both tax burden distribution and risk assessment are different. Tax return in Russia is quite evenly distributed between taxes, while in Italy two thirds of return come from two taxes only: personal income tax and value added tax, their return is considerably higher than that in Russia.

It is noteworthy that in Russia major tax burden falls onto companies (over a half of all tax revenues come from direct taxes only, and the taxpayers are companies). While in Italy personal income tax is an absolute leader in revenues (almost $40 \%$ of all revenues).

In the Italian tax system personal income tax shows the greatest risk. At the same time Italian tax risk assessment is comparable with the Russian one. It clearly shows the differences in the risk components of Russian and Italian tax systems: the assessment recognized as the maximum one within the framework of the Italian system, is comparable with the assessment of one of the least risky taxes in the Russian system.

What is common between the two systems is a relatively high level of risk of the value added tax as well as of profit tax in comparison with the risk of the system at large. 
At the same time in the Russian system there is a lucrative tax on mining, which increases the risk of the overall tax system.

Preliminary risk assessment of the tax systems on the basis of the weighted standard deviation shows that the Russian tax system risk exceeds the Italian tax system risk by 2.6 times. Though, using Markowitz's portfolio approach in order to assess the risk of the two taxation systems revealed a larger gap between the risk components of the two systems - by 4.2 times (for a comparable term of research).

It testifies to the fact that it is more reasonable to use a portfolio approach when assessing the risk of taxation systems, since it considers both the structure of tax revenues and their interconnection.

Another important conclusion of the research is the finding that tax revenues specification has almost no impact on the Italian tax system risk, while extending the term of research causes a considerable increase in the risk assessment.

The efficiency of the tax system evaluated by means of tax system effectiveness index proves to be by 4.88 times higher in the Italian tax system, which can be mainly explained by a different risk degree, while the levels of the Russian and Italian tax systems' return are comparable.

\section{Acknowledgements}

The research was funded by Russian Foundation for Humanities, as part project № 15-02-00638, "The relationship between income inequality and economic development in the regions of the Russian Federation".

\section{References}

Albrecht, W.G. (2013). Managing Tax Revenue Volatility. Conference Proceedings of the International Academy of Business and Public Administration Disciplines. Vol. 27. No.1.

Baer, W., Galvao, A.F. Jr. (2008). Tax burden, government expenditures and income distribution in Brazil. The Quarterly Review of Economics and Finance. Vol. 48, pp. 345-358.

Bunescu, L., Comaniciu, C. (2014). Analysis of Correlation Between Tax Revenues And Other Economic Indicators In European Union Member States. Studies in Business and Economics. Lucian Blaga University of Sibiu, Faculty of Economic Sciences. Vol. 9. Iss. 1. pp. 24-34.

Cornia, G.C, Nelson, R.D. (2010). State Tax Revenue Growth and Volatility. Regional Economic Development. Journal of Federal Reserve Bank of St. Louis. No. 6(1). pp. 23-58.

Deng, G.F., Lin, W.T., Lo, C.C. (2012) Markowitz-based portfolio selection with cardinality constraints using improved particle swarm optimization. Expert Systems with Applications. An International Journal. Vol. 39. Iss. 4. pp. 4558-4566.

Felix, R.A. (2008). The Growth and Volatility of State Tax Revenue Sources in the Tenth District. Economic Review of Federal Reserve Bank of Kansas City. pp. 63-88

Fricke, H., Süssmuth, B. Growth and Volatility of Tax Revenues in Latin America. CESifo Working Paper Series with number 3312.

Fukuda, K. (2008). Empirical evidence on intergenerational inequality of tax burdens in the U.S. and Japan. The Journal of SocioEconomics. Vol. 37, pp. 2214-2220.

Garrett, T.A. Evaluating state tax revenue variability: a portfolio approach. Working Papers of Federal Reserve Bank of St. Louis with number 2006-008.

Gujarathi, M., Feldmann, D. (2006). Dividend imputation system in industrialized countries: an examination of relative tax burdens. Advances in International Accounting. Vol. 19, pp. 243-259.

Haim, S., Shlomo, Y. (1984). Mean-Gini, Portfolio Theory, and the Pricing of Risky Assets. The Journal of Finance. Vol. 39. No. 5. pp. 1449-1468.

Malkina, M. Yu., Balakin, R.V. (2015). Correlation Assessment of Tax System Risk and Profitability in the Russian Regions. Ekonomika regiona [Economy of Region]. No. 3. pp. 241-255.

Malkina, M. Yu., Balakin, R.V. (2014). Analysis and evaluation of the Russian tax system risk based on the portfolio approach. Financial analytics: science and experience. No. 32(218). pp. $14-22$.

Salin, V., Patron, E., Stallmann, J. I. (2004). Rainy Day Funds for Municipalities Estimated with Value at Risk. North American Meetings of the Regional Science Association International. Seattle, Washington.

Seegert, N. (2012). Optimal Taxation with Volatility. A Theoretical and Empirical Decomposition. University of Michigan, Ann Arbor, MI.

Soleimani, H., Golmakani, H.R., Salimi, M.H. (2009). Markowitz-based portfolio selection with minimum transaction lots, cardinality constraints and regarding sector capitalization using genetic algorithm. Expert Systems with Applications. Vol. 36. Iss. 3, Part 1. pp. 5058-5063.

Wilford, D. S. (2012). True Markowitz or assumptions we break and why it matters. Review of Financial Economics. Vol. 21. Iss. 3. pp. 93-101. 